\title{
Optimization of triploid induction by the use of 6-DMAP for the oyster Crassostrea gigas (Thunberg)
}

\author{
A. GERARD, Y. NACIRI, J.-M. PEIGNON, C. LEDU \& \\ P. PHELIPOT IFREMER, Unité de Recherche en Génétique et Ecloserie, La \\ Tremblade, France
}

\begin{abstract}
A novel method using 6-dimethylaminopurine (6-DMAP) has recently been demonstrated to be a good triploid inductor for bivalve molluses. The effects of 6-DMAP concentration. timing of treatment after fertilization, and treatment duration on survival and triploid induction of Crassostrea gigas (Thunberg) embryos were cxamined. An influcnce of sperm concentration was also detected and discussed. Survival to D-stagc was inversely related to 6-DMAP concentration and the percentage of triploids was shown to be 6-DMAP dose dependent. Two optimal moments for treatment application were determined, corresponding to extrusions of the first and second polar bodies. Optimal treatment of $450 \mu \mathrm{mol} / \mathrm{l}$ 6-DMAP beginning $15 \mathrm{~min}$ after fertilization over a $10 \mathrm{~min}$ period yiclded mean survival to D-stage of $64 \%$ with a mean of $85 \%$ triploid production. As a comparison, a sample treated with $1 \mathrm{mg} / 1$ of cytochalasin $\mathrm{B}(\mathrm{CB}), 20 \mathrm{~min}$ after fertilization over a $15 \mathrm{~min}$ period, yielded a mean survival to D-stage of only $36 \%$ with a mean of $95 \%$ triploid production. The advantages of 6-DMAP over CB are clearly identified: this chemical is nol carcinogenic, cheaper than cytochalasin B and much casier to use as it is water soluble.
\end{abstract}

\section{Introduction}

Aquatic molluscs usually undergo growth reduction during their reproduclive season. Over the last 12 years, research has been undertaken on commercially important shellfish to develop efficient techniques to sterilize them. Numerous studies have been focused on triploidy induction because of the presumption that homologous chromosomes in the germ cells of adult triploids could not synapse at meiosis, insofar as triploids were expected to be sterile (Beaumont \& Fairbrother 1991 for review). Various methods have been used to induce triploidy in bivalve molluscs such as heat and pressure shock or chemical treatment with cytochalasin B. This latter technique has enjoyed success (Downing \& Allen 1987) and is now used routinely (Barber, Mann \& Allen 1992). A novel method using 6-dimethylaminopurine (6-DMAP) has recently been proposed to induce triploidy in bivalve molluses (Desrosiers, Gérard, Peignon, Naciri, Dufresne, Morasse, Ledu, Phélipot, Guerrier \& Dubé 1993). The puromycin analogue 6-DMAP had initially been reported to block the extrusion of polar bodies in oocytes of both starfish, Asteria rubens (L.) and Marthasterias glacialis (L.) (Néant \& Guerrier 1988). The first results on Crassostrea gigas (Thunberg), Mytilus edulis (L.) and Argopecten magellanicus (L.) confirmed the usefulness of this chemical (Desrosiers et al. 1993). This paper describes

Correspondence: Dr A. Gérard. IFREMER. Unité de Recherche en Génétique et Ecloseric, BP 133, Ronce les Bains, $17390 \mathrm{La}$ Tremblade, France. 
further experiments conducted to optimize the production of triploid Crassostrea gigas by examining the dosage, timing and duration of embryo treatment with 6-DMAP. A comparison with cytochalasin B treatment was also carried out.

\section{Materials and methods}

\section{Gamete handling and fertilization}

For all the experiments described in this paper, oysters, Crassostrea gigas, were conditioned i.e. brought to sexual maturation, in an open circulating system at $20^{\circ} \mathrm{C}$. Sperm and oocytes were stripped from the gonads. At least four males and four females were used for each experiment. The stripped gametes were filtered on a $45 \mu \mathrm{m}$ sieve for males and on a $75 \mu \mathrm{m}$ sieve for females and then resuspended in $3 \mu \mathrm{m}$ filtered sea water. The oocyte number was adjusted to a concentration of $100 / \mathrm{ml}$ and fertilization was achieved with a ratio of 50 spermatozoa per ovum for the first four experiments and with a ratio of 100 spermatozoa per ovum for the last experiment.

\section{Triploidy induction}

For triploidy induction, oyster embryos were incubated with 6-DMAP at different concentrations ranging from 0 to $600 \mu \mathrm{mol} / \mathrm{l}$. The time of application ranged from 5 to $40 \mathrm{~min}$ after fertilization. For treatment duration, four periods ranging from 10 to $25 \mathrm{~min}$ were tested. The embryos were concentrated and treated in 11 of sea water in beakers and after each treatment, the 6-DMAP was thoroughly washed off the embryos by filtering the samples on a $10 \mu \mathrm{m}$ sieve. All the experiments were conducted at $25^{\circ} \mathrm{C}$ with reference to the routinely used cytochalasin B (CB) treatments (Allen, Downing, Chaiton \& Beattie 1986; Downing \& Allen 1987).

In the first experiment, embryos were incubated with 6-DMAP at four different concentrations: $150,300,450$ and $600 \mu \mathrm{mol} / \mathrm{l}$. The treatment was applied $15 \mathrm{~min}$ after fertilization and lasted for $20 \mathrm{~min}$. In the second experiment, the treatment was applied at eight different times after fertilization. A concentration of $300 \mu \mathrm{mol} / /$ was chosen and treatments lasted $20 \mathrm{~min}$, at $5,10,15,20,25,30,35$ and $40 \mathrm{~min}$ after fertilization. The third and fourth experiments analysed the effect of treatment durations and were performed on the same gamete pools. Four periods $(10,15,20$ and $25 \mathrm{~min})$ were tested at $15 \mathrm{~min}$ after fertilization with two 6-DMAP concentrations: 300 and $400 \mu \mathrm{mol} / \mathrm{l}$. An untreated sample was kept as control for all the experiments. The fifth experiment consisted of a comparison between 6-DMAP and cytochalasin B treatments. A control was made and two samples were respectively treated by 6-DMAP and CB. The results of the previous four experiments were used to choose the 6-DMAP treatment parameters, recalling that the aim was to maximize the triploid percentage and the larval survival for each treatment. The 6-DMAP treatment was then applied $15 \mathrm{~min}$ after fertilization and lasted $10 \mathrm{~min}$ at a concentration of 450 umol/l. For CB treatment, some preliminary experiments (unpublished data) showed that the best triploid percentages were usually obtained for $15 \mathrm{~min}$ treatments applied $20 \mathrm{~min}$ after fertilization. These conditions differ slightly from those used by Downing \& Allen (1987), who usually applied $15 \mathrm{~min}$ CB treatments $30 \mathrm{~min}$ after fertilization. Following the common method (Beaumont \& Fairbrother 1991), a dosage of $1 \mathrm{mg}$ 
CB dissolved in $1 \mathrm{ml}$ dimethyl sulfoxide (DMSO) per litre of sea water was chosen. Embryos were sieved after treatment, rediluted to 11 , and $1 \mathrm{ml}$ DMSO was added for an additional $15 \mathrm{~min}$.

\section{Larval and spat culture}

The effects of both 6-DMAP and CB treatments on growth and survival rates were analysed in larvae. Following the treatments, the larvae were reared at a density of about $50 \mathrm{larvae} / \mathrm{ml}$ for $24 \mathrm{~h}$ in $30-\mathrm{l}$ tanks at $24^{\circ} \mathrm{C}$. The D-shaped larvae were then collected, counted and diluted to $5 \mathrm{larvae} / \mathrm{ml}$. Every other day, the sea water was changed. Larvae were fed with a mixed diet of Isochrysis sp., Pavlova lutheri and Chactoceros calcitrans at a rate of $20 \mathrm{cells} / \mu \mathrm{l} / \mathrm{day}$ for each algal species. Size and percentage survival were determined every 2 or 3 days until metamorphosis. The eyed larvae were then transferred onto $150 \mu \mathrm{m}$ sieves with a flow-through system of unfiltered sea water. Oyster shell cultch was used for settlement of the larvae. The seawater was enriched every day with a mixture of three algal species out of the six species routinely produced in the hatchery (Isochrysis sp., Isochrysis (Tahiti clone), Platymonas suecica, Pavlova lutheri, Chaetoceros (Pumilum clone) and Chaetoceros calcitrans). The sieves were washed daily and changed regularly, following the spat growth.

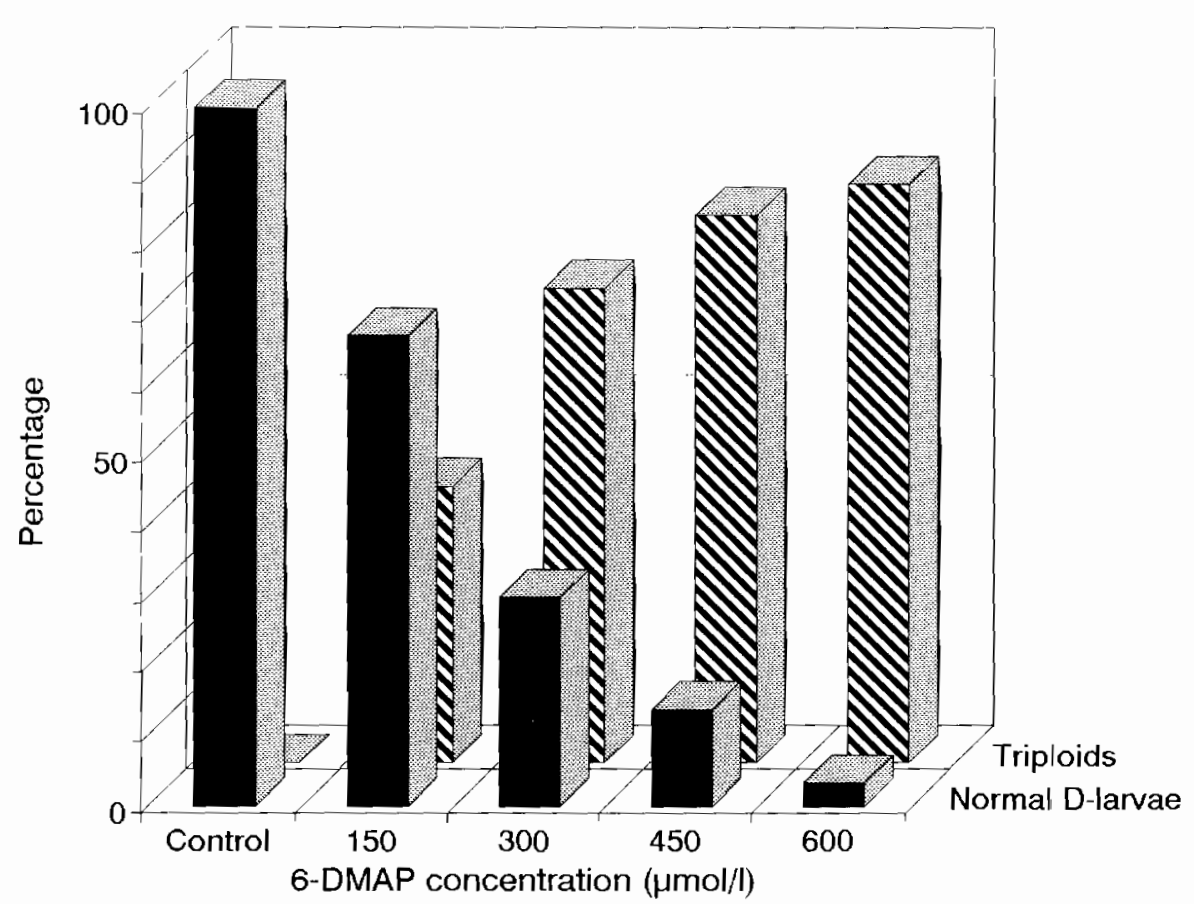

Figure 1. Eflect of 6-DMAP concentration on percentages of triploid and normal D-shaped larvac with treatments applicd 15 min after fertilization over a 20 min period. 
Cytological procedures and ploidy determinations

In order to follow the meiotic and mitotic stages reached at various times after fertilization, embryo samples were fixed for $1 \mathrm{~h}$ in a $2 \%$ formaldehyde solution prepared in a glucosamine-acetate buffer. Embryos were then washed with fixative-free buffer and nuclear DNA was stained with $0.5 \mu \mathrm{g} / \mathrm{ml}$ of Hoechst 33258 (Dubé, Schmidt, Johnson \& Epel 1985). Observations were carried out with an Olympus epifluorescence microscope. This technique has recently been acquired in our laboratory and therefore it was only applied for the last three experiments.

The ploidy levels were determined by image analysis on a pooled larval sample. This technique gives the optical density of Feulgen-stained nuclei (Gérard, Peignon \& Chagot 1991). By comparison with the mean optical density of a diploid sample, it is possible to determine the percentage of triploid nuclei of any 6-DMAP or CB-treated sample.

\section{Results}

\section{Effect of dosage}

Results shown in Fig. 1 indicate that the triploid percentage is dose dependent. The triploid percentage varies from $40 \%$ for a 6 -DMAP concentration of $150 \mu \mathrm{mol} / 1$ to $83 \%$ for a concentration of $600 \mu \mathrm{mol} / 1$. The number of normal D-shaped larvae for treated samples was considered relative to the number of normal larvae in the control. This

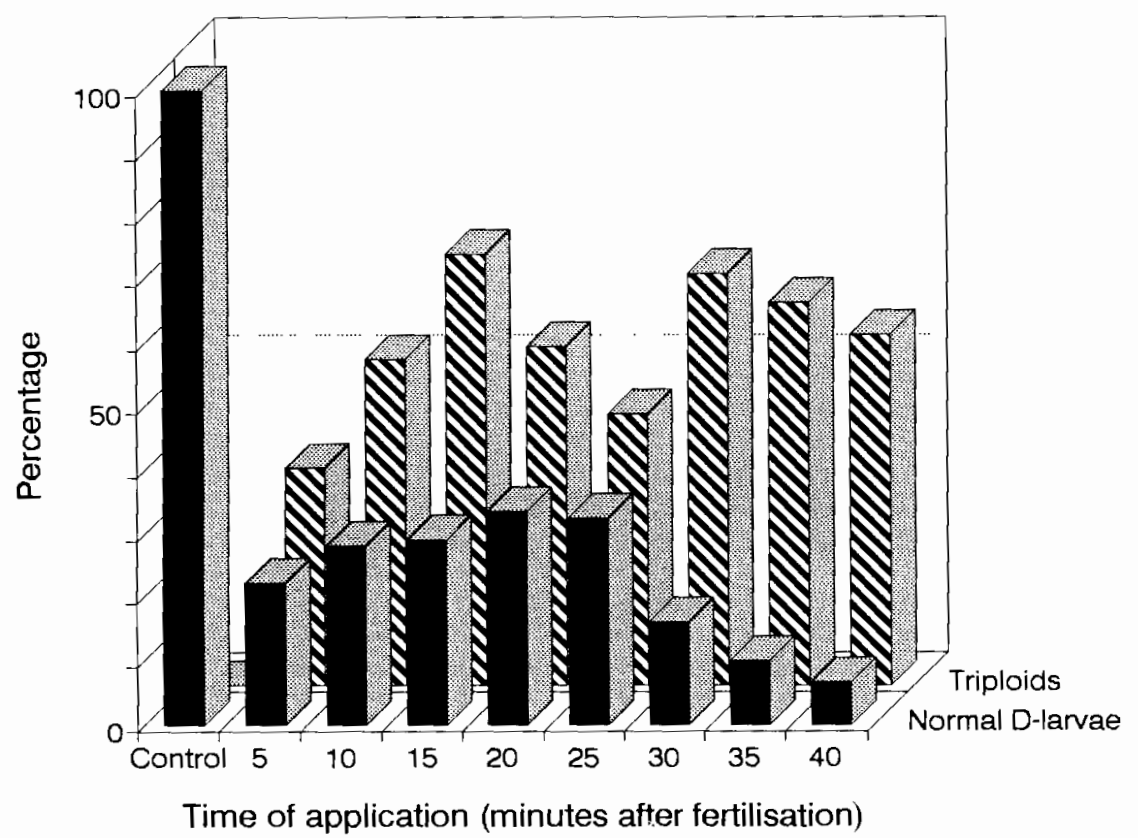

Figure 2. Effect of time of treatinent application on perecntages of triploid and normal D-shaped larvac with a 6-DMAP concentration of $300 \mathrm{\mu mol} / 1$ applied over a period of $20 \mathrm{~min}$. 
percentage decreases from $100 \%$ for the control to $3 \%$ for the $600 \mu \mathrm{mol} / /$ treated sample. For further experiments two concentrations were chosen: 300 and $450 \mu \mathrm{mol} / \mathrm{l}$.

\section{Effect of time of application}

Figure 2 shows that triploid percentages vary depending on the moment of treatment application. With a concentration of $300 \mu \mathrm{mol} / 1$ and a $20 \mathrm{~min}$ application, two optimal inductions were obtained for treatments applied $15 \mathrm{~min}$ and $30 \mathrm{~min}$ after fertilization. For those two samples, triploid percentage was respectively $68 \%$ and $65 \%$. The percentage of normal D-shaped larvae was maximal for a treatment applied $20 \mathrm{~min}$ after fertilization $(34 \%)$. For the two former treatments the percentage of normal larvae was respectively $29 \%$ and $16 \%$.

\section{Effect of treatment duration}

The same parents were used for the third and fourth experiments. Results obtained with 6-DMAP concentrations of 300 and $450 \mu \mathrm{mol} / 1$ applied 15 minutes after fertilization are shown respectively in Figs 3 and 4 . For both concentrations, Figs 3 and 4 indicate that long treatments decrease both the triploid percentage and that of normal larvae. For a $300 \mu \mathrm{mol} / \mathrm{l}$ concentration, the best performance regarding those two ratios was achieved for a $15 \mathrm{~min}$ duration when $51 \%$ of triploids and $71 \%$ of normal larvae were obtained. For

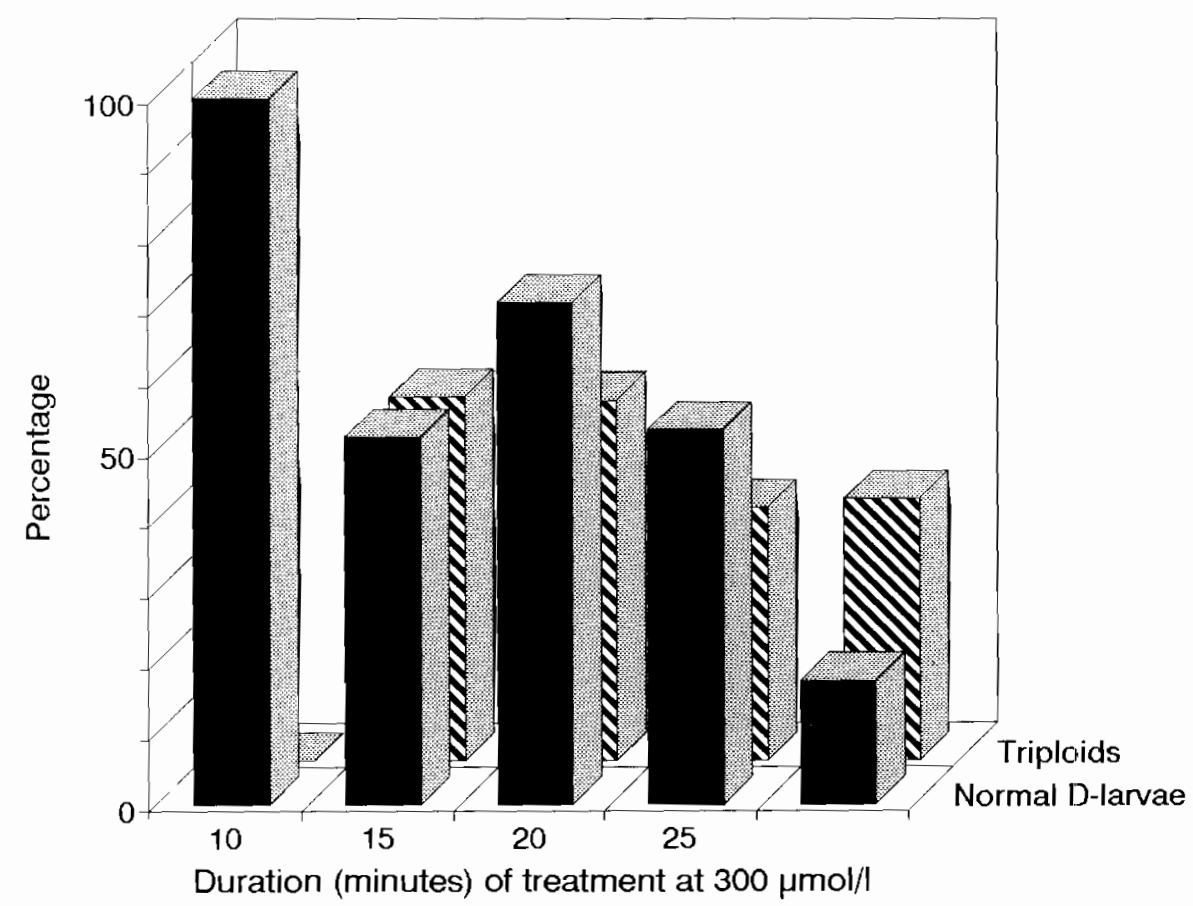

Figure 3. Effect of treatment duration on perecntages of triploid and normal D-shaped larvac with a 6-DMAP concentration of $3(x) \mu \mathrm{mol} / \mathrm{l}$ and a treatment applicd $15 \mathrm{~min}$ after ferilization. 
the 10 min treatment, the same triploid percentage was obtained $(52 \%)$ but with a lower ratio of normal larvae $(52 \%)$. For a $450 \mu \mathrm{mol} / 1$ concentration, Fig. 4 indicates that the best result was obtained for the $10 \mathrm{~min}$ treatment, with $72 \%$ of triploids and $58 \%$ of normal larvae. The kinetics of the extrusions of the polar bodies shows that oocyte fertilization was not synchronized (Fig. 5): the extrusion of the first polar body (PB1) occurred between 10 and $30 \mathrm{~min}$ after fertilization whereas the extrusion of the second polar body (PB2) occurred between 20 and $45 \mathrm{~min}$. Treatments were then applied when about $10 \%$ of the PB1 were already extruded.

\section{Comparison between $C B$ and 6-DMAP treatments}

A treatment with a 6-DMAP concentration of $450 \mu \mathrm{mol} / 1$ applied at $15 \mathrm{~min}$ over a period of $10 \mathrm{~min}$ was chosen for the comparison with $\mathrm{CB}$ induction which was applied at $20 \mathrm{~min}$ over a $15 \mathrm{~min}$ period. Figure 6 shows that the CB treatment gave more triploids $(95 \%)$ than the 6-DMAP one $(85 \%)$. Nevertheless, the percentage of normal D-shaped larvae is higher for 6-DMAP treatments $(64 \%)$ than for CB treatment $(36 \%)$. The kinetics of the extrusions of the first (PB1) and second (PB2) polar bodies (Fig. 7) shows that the 6-DMAP treatments were applied $15 \mathrm{~min}$ after fertilization, when about $26 \%$ of the oocytes had extruded their first polar body, whereas the $\mathrm{CB}$ treatment was applied 20 minutes after fertilization, when $65 \%$ of the cells had extruded their PB1. Fertilization seems to have been much more synchronized than for the former experiments. At

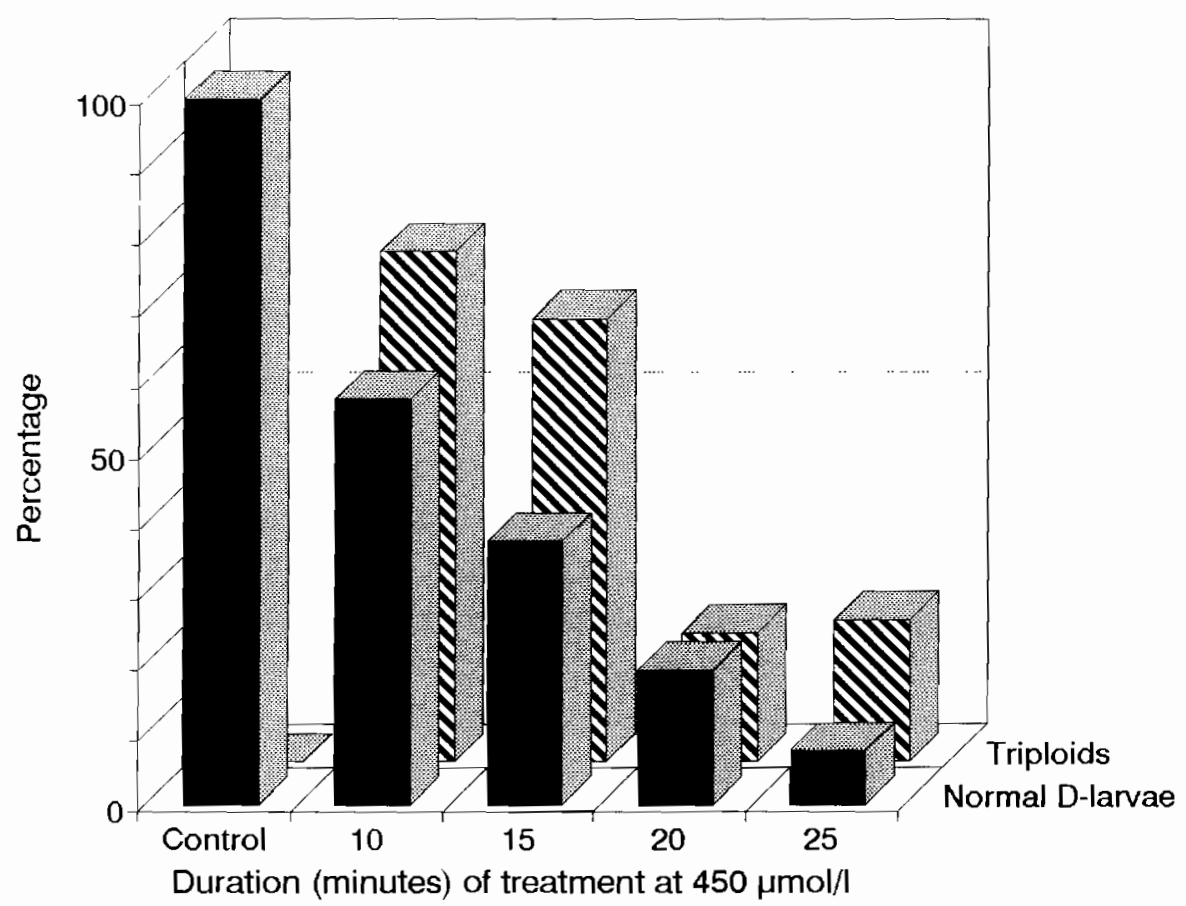

Figure 4. Effect of treatment duration on percentages of triploid and normal D-shaped larvac with a 6-DMAP concentration of $450 \mu \mathrm{mol} / \mathrm{l}$ and a treatment applied $15 \mathrm{~min}$ after fertilization. 


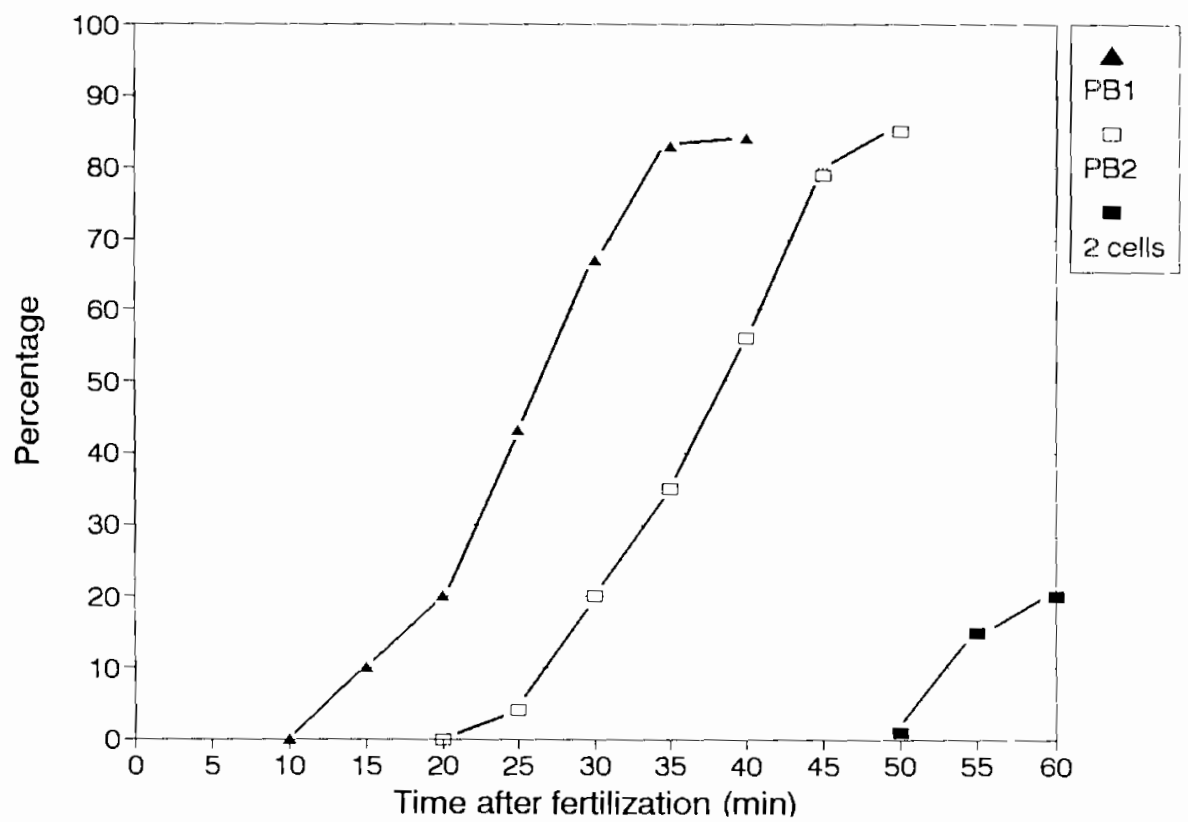

Figure 5. Kinetics oi extrusion of the first and second polar bodies (PB1 and PB2) at $25^{\circ} \mathrm{C}$ for the untreated control of experiments 3 and 4 .

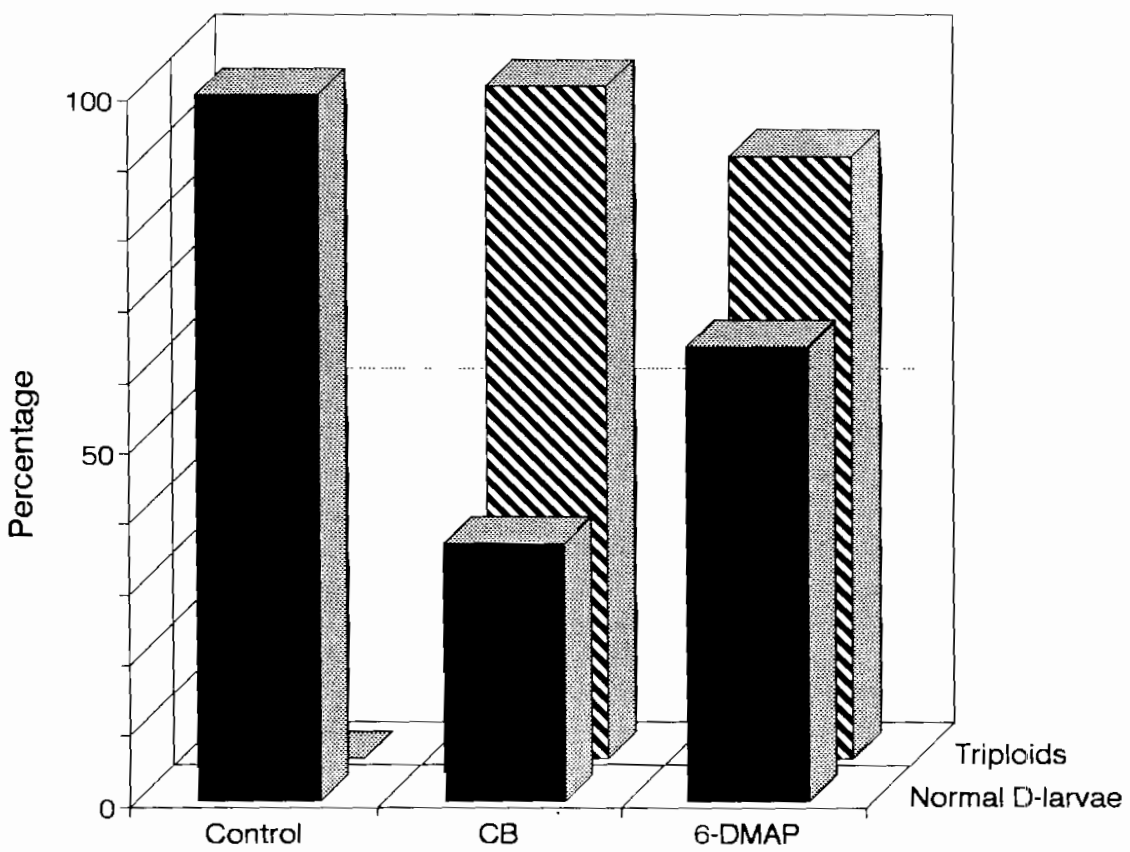

Figure 6. Elfeets of 6-DMAP and CB treatments on pereentages of triploid and normal D-shaped larvac 


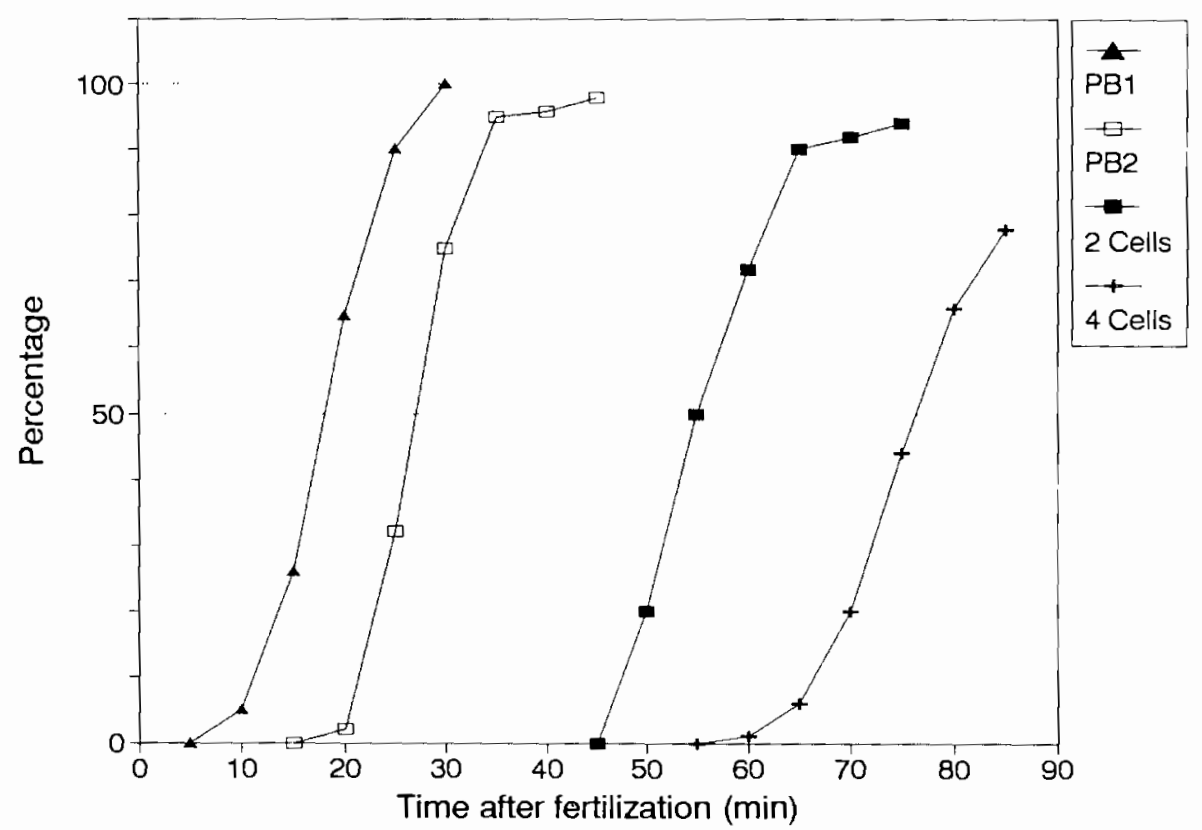

Figure 7. Kinetics of extrusion of the first and second polar bodies ( $P B 1$ and $P B 2$ ) at $25^{\circ} \mathrm{C}$ for the untreated control of experiment 5 .

metamorphosis, embryo survival was higher for the control $(27 \%)$ than for the 6-DMAPtreated sample (19\%) which, in turn, was higher than the CB-treated sample (11\%) (Fig. 8). For survival, the only significant difference $(\alpha=0 \cdot 1 \%)$ occurred between the control and the CB-treated sample. After 45 days of rearing, growth of the two treated samples was not significantly different $(\alpha=5 \%)$ from each other. The only significant difference $(\alpha=1 \%)$ was between the mean larval size of the control and the mean larval size of the 6-DMAPtreated sample (Fig. 9).

\section{Discussion}

Results are consistent with the first experiments conducted on Crassostrea gigas by Desrosiers et al. (1993). Triploid percentage depends on 6-DMAP dosage, moment of application and treatment duration. Similar results were also found by Downing \& Allen (1987) for $\mathrm{CB}$ inductions. As the 6-DMAP concentration was increased from 150 to $600 \mu \mathrm{mol} / 1$, triploid percentage increased from $40 \%$ to $83 \%$ and normal $\mathrm{D}$-shaped larvae ratio decreased from $67 \%$ to $3 \%$. Short-duration treatments ( 10 and $15 \mathrm{~min}$ ) gave the best triploid percentage and the best normal D-shaped larvae percentage. The best time for treatment application seems to be at $15 \mathrm{~min}$ after fertilization. For a concentration of $450 \mu \mathrm{mol} / \mathrm{l}$ and a treatment applied $15 \mathrm{~min}$ after fertilization over a $10 \mathrm{~min}$ period, $85 \%$ of triploids were obtained. The normal $D$-shaped larvae percentage increased from the early treatment to the treatments applied 20 or $25 \mathrm{~min}$ after fertilization and then decreased for the later treatments. 


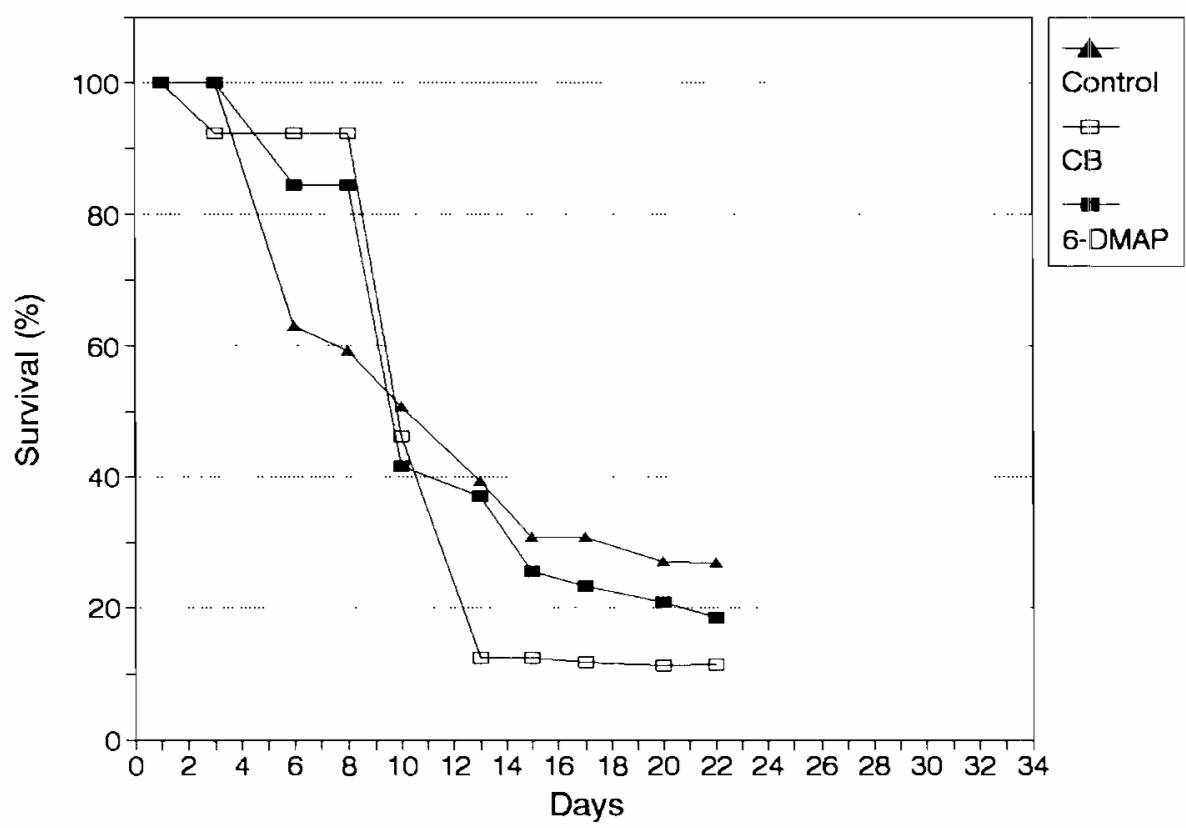

Figure 8. Kinetics of cmbryo survival for the comparative experiment between 6-DMAP and CB treatments.

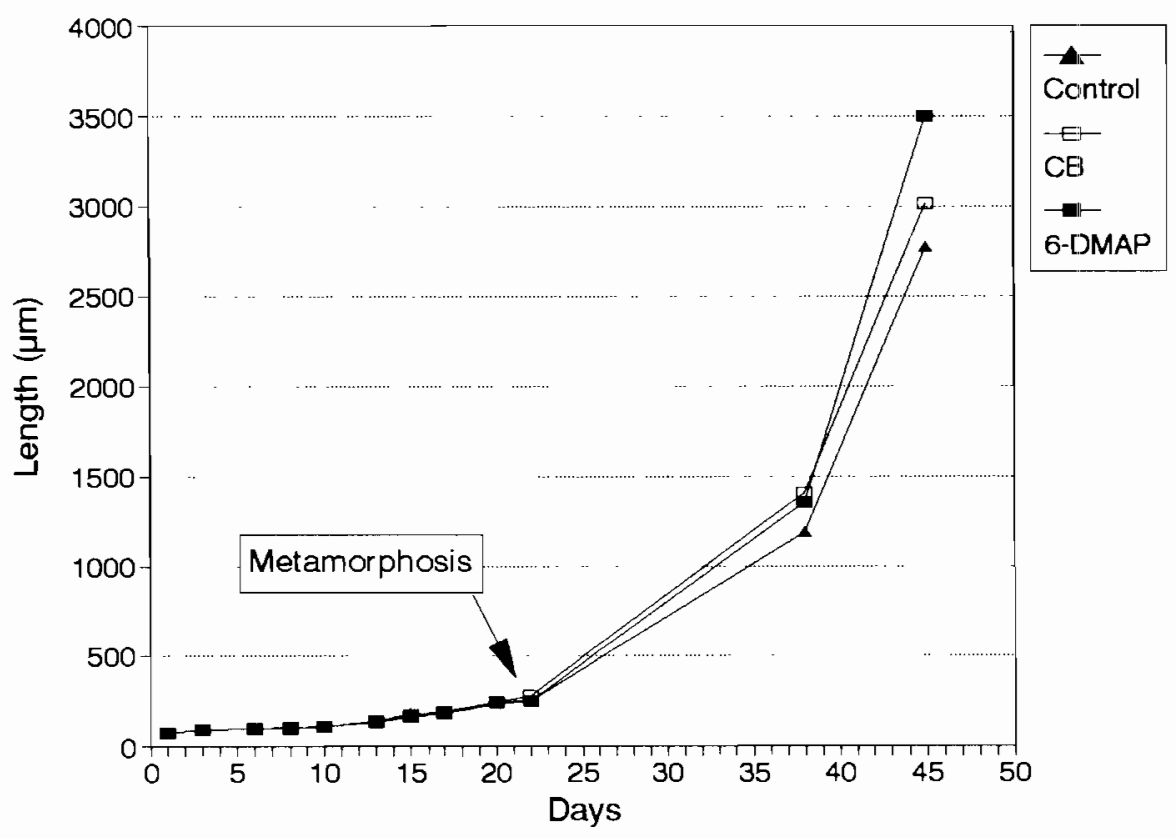

Figure 9. Kinetics of growth for the comparative experiment between 6-DMAP and CB treatments. 
A comparison of Figs 5 and 7 shows an improvement in the synchronization of polar body extrusion. The only parameter which changed between experiments 3 and 4 and experiment 5 was the sperm concentration, which was increased from 50 to 100 spermatozoa per ovum. It can then be deduced that a higher spermatozoa/ovum ratio led to a better and more synchronized fertilization. Such a synchronization seems also to affect the triploid percentage. In the fourth experiment, $72 \%$ of triploids were obtained with a $450 \mu \mathrm{mol} / \mathrm{l}$ treatment applied $15 \mathrm{~min}$ after fertilization over a $10 \mathrm{~min}$ period. For the fifth experiment, application of the same treatment with a higher sperm concentration gave a triploid percentage of $85 \%$.

As explained above, the parameter levels $(450 \mu \mathrm{mol} / 1,15 \mathrm{~min}, 10 \mathrm{~min})$ were chosen for the 6-DMAP/CB comparison experiment. According to the kinetics, this moment of application corresponds to the first polar body extrusion for about $25 \%$ of the oocytes. Although the 6-DMAP induction did not give the best triploid percentage $85 \%$ against $95 \%)$, it must be noticed that the best survival and the higher normal D-shaped larvae ratio were obtained for the 6-DMAP treatment. It must also be underlined that 6-DMAP is much less dangerous to human health than $\mathrm{CB}$, which is known to be carcinogenic. Furthermore, 6-DMAP is easier to use, as it is water soluble, and requires no previous DMSO dilution. 6-DMAP is less expensive than CB.

For CB inductions, Allen \& Downing (1986), Downing \& Allen (1987), and Allen et al. (1986) obtained triploid ratio ranging from $90 \%$ to $100 \%$. In their review, Beaumont \& Fairbrother (1991) give a mean of $83 \%$ of triploid larvae according to the main experiments conducted on Crassostrea gigas and 6-DMAP induction appears to be close to such performances.

The results clearly point out 6-DMAP treatments as the simplest, least expensive and most efficient technique to induce triploidy in Crassositea gigas. No doubt the slightly lower performance obtained with 6-DMAP treatment compared with CB treatment could be improved. More experiments should be conducted with the same parameters, and the influence of temperature or spermatozoa concentration should also be investigated.

\section{Acknowledgments}

We thank the Regional Council of Poitou-Charentes region for supporting this work. We also thank Dr P. Guerrier and the two anonymous referees for their helpful suggestions and advice.

\section{References}

Allen S.K. Jr \& Downing S.L. (1986) Performance of triploid Pacific oysters, Crassostrea gigas (Thunberg). I. Survival, growth, glycogen content and sexual maturation in yearlings. Journal of Experimental Marine Biology and Ecology 102, 197-208.

Allen S.K. Jr. Downing S.L., Chaiton J. \& Bcattic J.H. (1986) Chemically and pressure-induced triploidy in the Pacific oyster Crassostrea gigas. Aquaculture 57, 359-365.

Barber B.J., Mann R. \& Allen S.K. Jr (1992) Optimization of triploid induction for the oyster Crassostrea virginica (Gmelin). Aquaculture 106, $21-26$.

Beaumount A.R. \& Fairbrother J.E. (1991) Ploidy manipulation in mollusean shellfish: a review. Journal of Shellfish Research 10(1), 1-18.

Desrosicrs R.R., Gérard A., Pcignon J.-M., Naciri Y., Dufresne L., Morasse J.. Ledu C., Phélipot P.. Gucrrier 
P. \& Dubć F. (1993) A novel method to produce triploid embryos in bivalve molluses by the use of 6-dimethylaminopurine. Journal of Experimental Marine Biology and Ecology 170, 29-43.

Downing S.L. \& Allen S.K. Jr (1987) lnduced triploidy in the Pacific oyster (rassostrea gigas: optimal treatments with cytochalasine B depend on temperaturc. Aquaculture 61, 1-15.

Dubé F., Schmidt T. Johnson C.H. \& Epcl D. (1985) The hic rarchy of requirements for an elevated intracellutar pH during carly development of sea urchin embryos. Cell 40, 657-666.

Gérard A.. Pcignon J.-M. \& Chagot D. (1991) Contrôle de la plö̈die par imagcric numérnque dans les expériences d'induction de la triplö̈die chez les mollusques bivalves. Congrès CIEM La Rochelle. PAPER ICES C.M. 1991/F:12 Ré1. K, Mariculture Comminee. 6 pp.

Néant I. \& Guerrier P. (1988) 6-Dimethylaminopurine blocks starfish oocyte maturation by inhibiting a rclevant protein kinase activity. Experimental Cell Research 176, 68-79. 
